\title{
SCHOOL HYGIENE.
}

Published under the auspices of

The Medical Officers of Schools Association. OUARTERLY. ANN. SUB. $4 / 6$ post free.

ADLARD \& SON \& WEST NEWMAN, Ltd., 23, Bartholomew Close, London, E.c. 1.

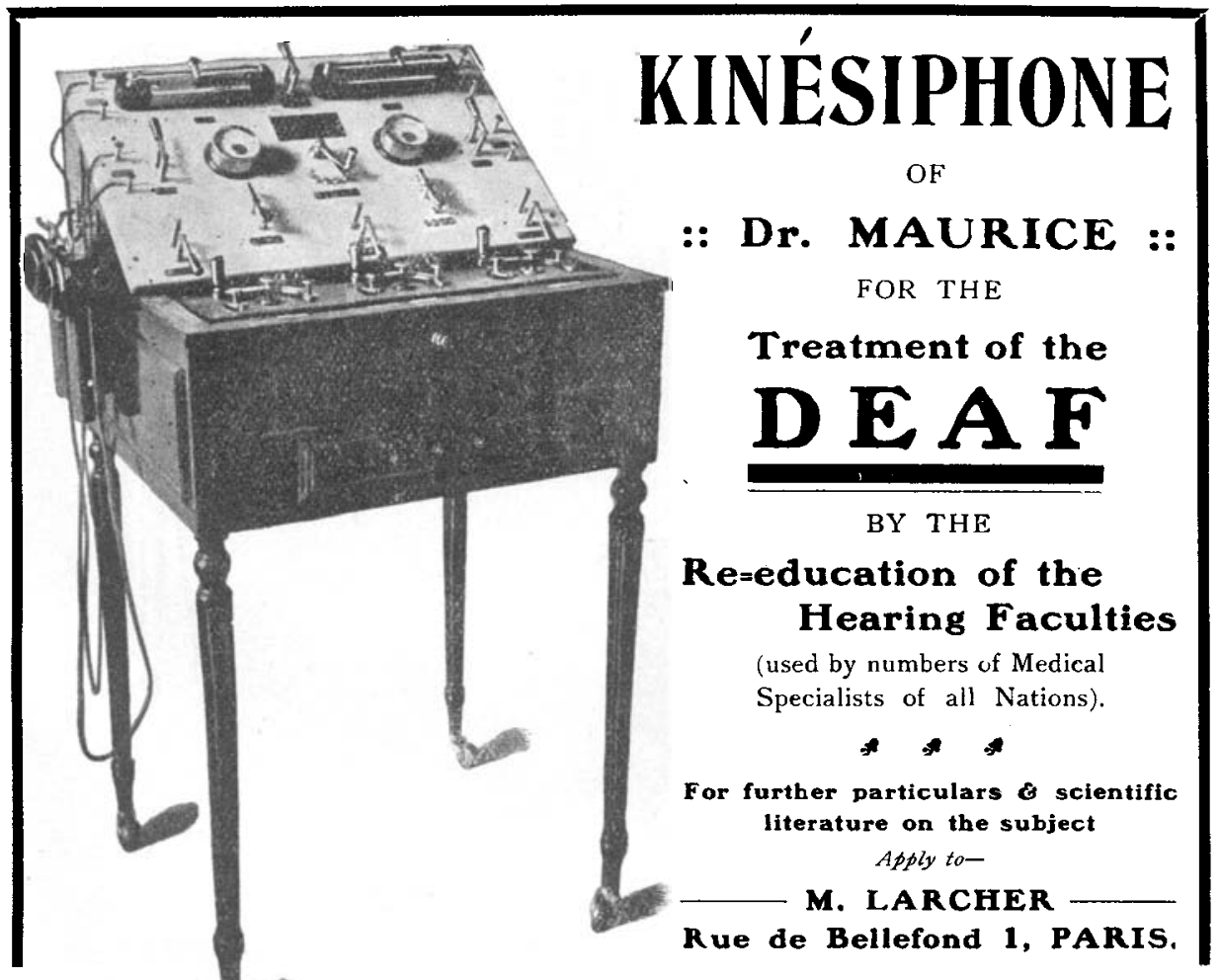


vi

\section{Dr. Irwin Moore's UNIVERSAL FORCEPS}

For Removing Foreign Bodies from the Esophagus, Trachea, or. Bronchi. And ENDOSCOPIC CUTTING FORCEPS or SHEARS And

For Cutting through Tooth-plates, Pins, or Bones.

Dr. William Hill's EXPANDING ESOPHAGOSCOPE For assisting in Removal of Impacted Tooth-plates, etc. See LANCET, May 13 th, 1916.
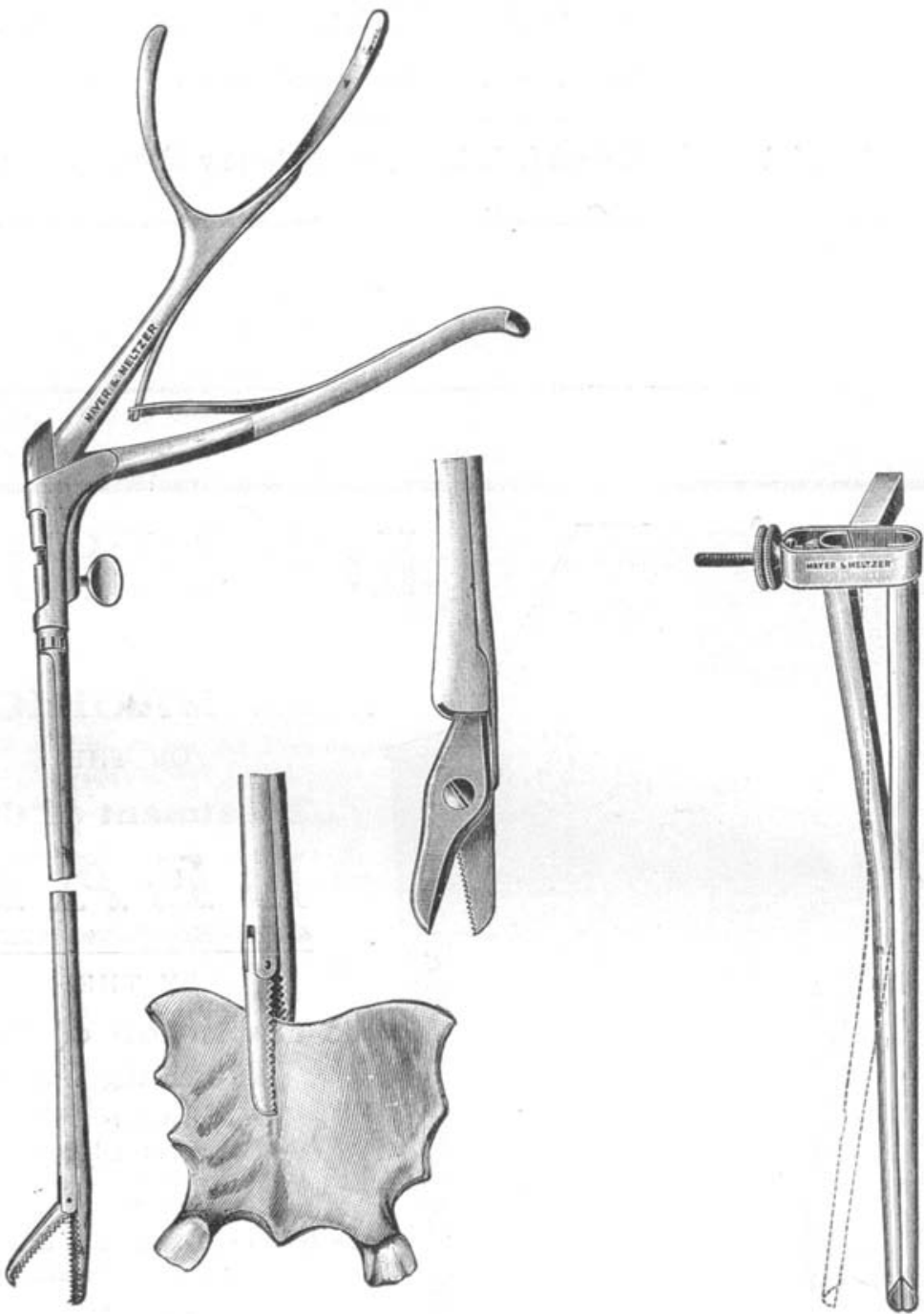

FULL PARTICULARS ON APPLICATION. 
MAYER \& MELTZER draw attention to change of title and address.

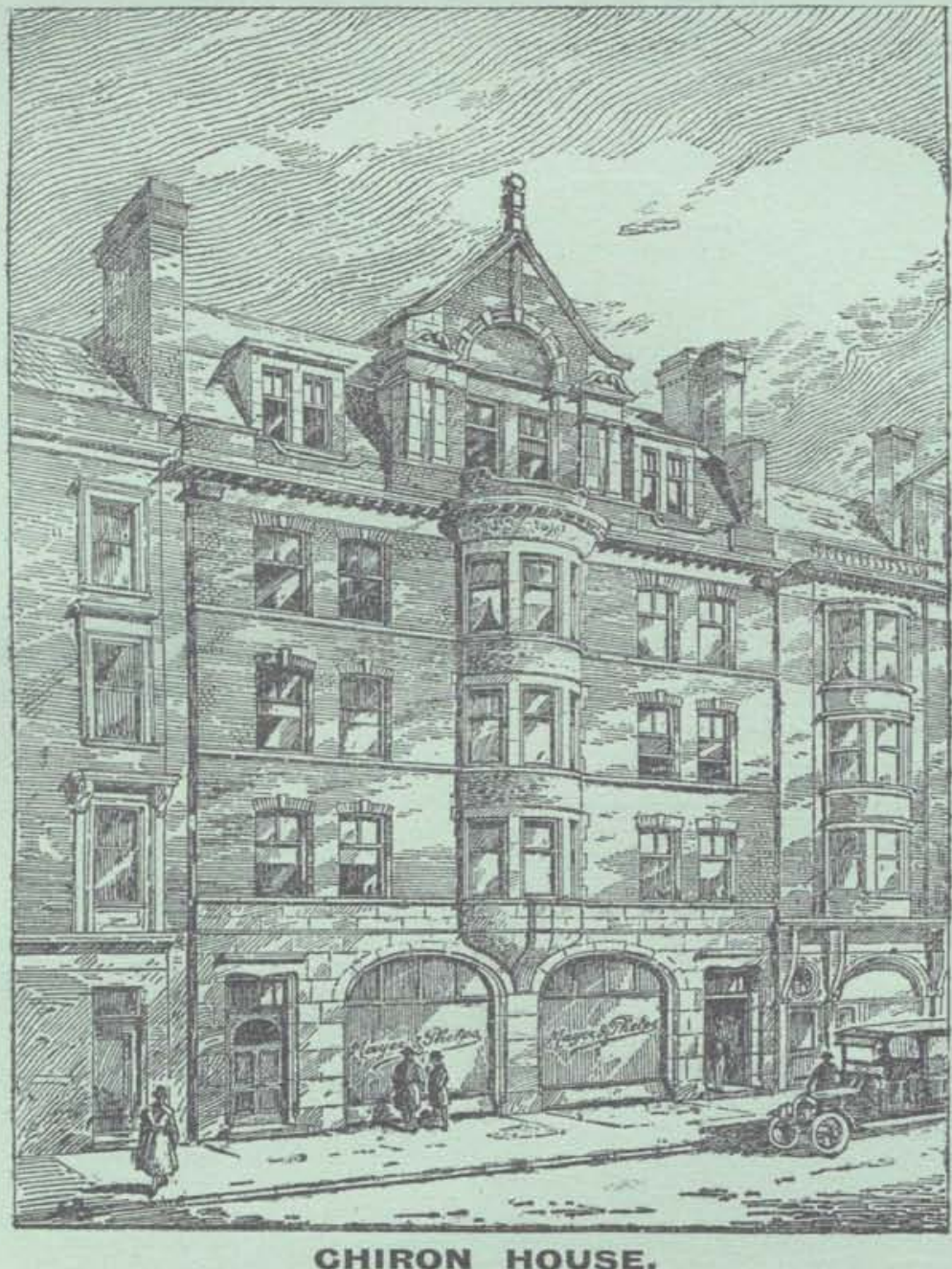

MAYER \& MELTZER have removed to the above premises where their business will be carried on in future under the name of MAYER \& PHELPS, the two Partners who have been the sole proprietors and managers for many years (Meltzer's interest ceased at his death thirty-five years ago).

Larger Showrooms are available for the display of Instruments, Aseptic Furniture, etc., and, as in the past, no effort will be spared to maintain and enhance the reputation for design and workmanship of Mayer's Surgical Tools.

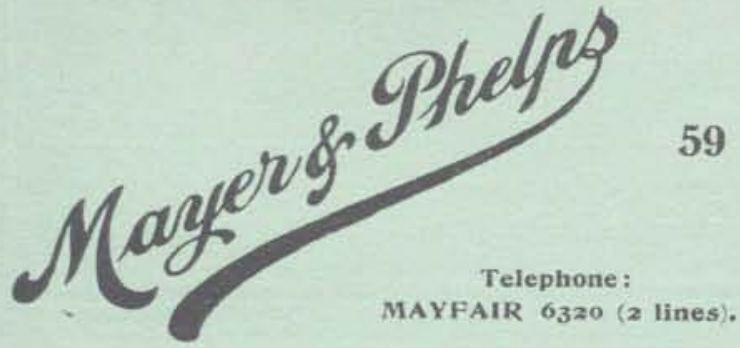

D

\section{CHIRON HOUSE,}

59 and 61, New Cavendish Street, LONDON, W. 1.

Telegrams :

"TREPHINE, WESDO, LONDON." 


\section{The "Allenburys" (мвитатво) Throat Pastilles}

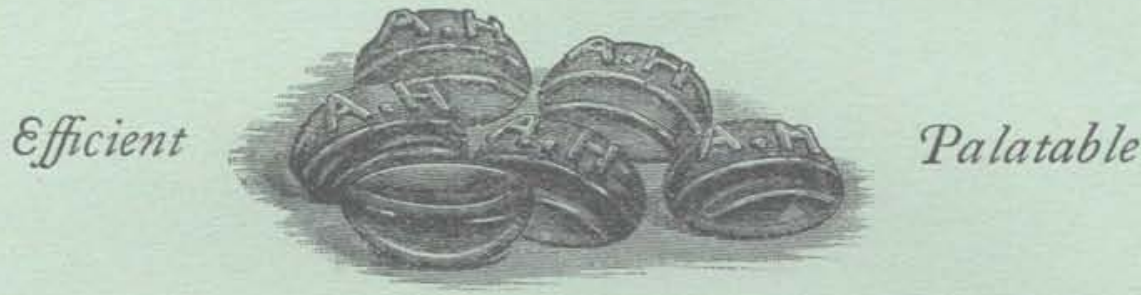

The basis of the "Allenburys" Throat Pastilles is a special pâte de jujube. The pastilles are demulcent, soluble and palatable, and contain accurate amounts of pure active drugs. They dissolve slowly and uniformly, so ensuring the thorough suffusion of the mucous membrane, and the prolonged continuous direct effect of the active ingredients.

The following pastilles are largely used, and have been found from long practical experience to be very efficacious.

No. 9. Menthol, Cocaine and Red Gum

No. 23. Eucalyptus and Red Gum

No. 28. Compound Guaiacum

Eucalyptus, $\frac{1}{2}$ minim of the Oil : Red Gum, gr. 1

No. 29. Compound Rhatany

Extract of Khatany. gr. 2: Cocaine Hydrochlor, Br. 1/40th

No. 38. Chlorate of Potash, Borax and Cocaine

No. 75. Formaldehyde and Menthol

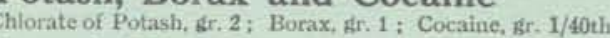

Formaldehyde, min. 1; Menthol, $8 \mathrm{r}$. 1/40th

No. 77. Formaldehyde and Cinnamon Oil

Formaldehyde, min. 1; OL. Cinnamon, min. $\frac{1}{2}$

A detailed list of the varieties made will be sent on application.

IMPORTANT.-To ensure the supply of these active and reliable medicinal products, medical men should designate the

"ÁLZENBURYS" Pastilles in their prescriptions.

\section{Allen \& Hanburys Ltd. London}

NIAGARA FALLS, N.Y. TORONTO. BUENOS AIRES. DURBAN. SYDNEY. 